\title{
BMJ Open Prevalence, discomfort and self-relief behaviours of painful diabetic neuropathy in Taiwan: a cross-sectional study
}

\author{
Sui-Whi Jane, ${ }^{1}$ Ming-Shyan Lin, ${ }^{2}$ Wen-Nan Chiu, ${ }^{3}$ Randal D Beaton, ${ }^{4}$ \\ Mei-Yen Chen ${ }^{5,6,7}$
}

To cite: Jane S-W, Lin M-S, Chiu W-N, et al. Prevalence, discomfort and self-relief behaviours of painful diabetic neuropathy in Taiwan: a cross-sectional study. BMJ Open 2016;6:e011897. doi:10.1136/bmjopen-2016011897

- Prepublication history for this paper is available online. To view these files please visit the journal online (http://dx.doi.org/10.1136/ bmjopen-2016-011897).

Received 15 March 2016 Revised 15 August 2016 Accepted 13 September 2016

CrossMark

For numbered affiliations see end of article.

Correspondence to Dr Mei-Yen Chen; meiyen@ mail.cgust.edu.tw

\section{ABSTRACT}

Objectives: To explore the prevalence, discomfort, and self-relief behaviours of painful diabetic neuropathy (PDN) among rural community residents with type 2 diabetes.

Design: A community-based, cross-sectional study. Setting: This study was part of a longitudinal cohort study of a nurse-led health promotion programme for preventing foot ulceration in Chiayi County, Taiwan.

Participants: Six hundred and twenty-eight community adults with type 2 diabetes participated in this study.

Outcome measures: Parameters assessed included peripheral neuropathy, peripheral vasculopathy, glycaemic control and metabolic biomarkers. Statistical analyses included descriptive statistics and a multivariate logistic regression model.

Results: About $30.6 \%$ of participants (192/628) had PDN. Factors associated with PDN included an abnormal ankle brachial index (ABI; OR=3.4; $95 \% \mathrm{Cl}$ 1.9 to $6.2 ; p<0.001)$, Michigan neuropathy screening index (OR=1.69; $95 \% \mathrm{Cl} 1.0$ to 2.6; $\mathrm{p}=0.021$ ),

triglyceride level $(\mathrm{OR}=1.61 ; 95 \% \mathrm{Cl} 1.0$ to 2.4 ; $\mathrm{p}=0.036)$ and being female $(\mathrm{OR}=1.68 ; 95 \% \mathrm{Cl} 1.1$ to 2.4; $p=0.022$ ). PDN was characterised by uncomfortable feelings of prickling, stinging or burning pain and inexplicable dullness around the base or dorsal areas of the feet, but received little attention or treatment from primary healthcare providers.

Conclusions: A high prevalence of PDN was found in rural community residents with type 2 diabetes and the healthcare workers provided little attention to, or treatment of, discomfort. It is important to identify high-risk groups with PDN early in order to prevent foot ulceration and reduce the incidence of amputation of the extremities. It is also urgent to develop appropriate treatment and self-relief behaviours to halt or reverse the progression of PDN for this population living in rural areas.

\section{INTRODUCTION}

The World Health Organization reported that 347 million people worldwide had diabetes

\section{Strengths and limitations of this study}

- Few studies have focused on describing feelings of discomfort and self-relief behaviours of painful diabetic neuropathy (PDN), particularly in diabetic residents in rural areas.

- Unrelieved PDN can result in intolerable pain, substantial morbidity and disrupt patients' quality of life.

- A high prevalence of PDN was found in rural community residents with type 2 diabetes, and many feelings of discomfort received little attention or treatment by healthcare providers.

- The results can be used to highlight the value of a nurse-led health promotion programme and multidisciplinary approach for the early detection of PDN in adults with diabetes in a rural community.

- Participants were recruited from only one county and by non-random sampling, which limits the generalisability of the study findings.

in $2008,{ }^{1}$ and it was postulated that this would increase by $50 \%$ in Asia, the Middle East and Africa by $2030 .^{2}$ In Taiwan, type 2 diabetes is the fourth leading cause of death with a standardised mortality rate of $26.9 / 10^{5}$, which is higher than Korea $\left(21.8 / 10^{5}\right)$, the USA $\left(14 / 10^{5}\right)$, Singapore $\left(13.4 / 10^{5}\right)$, the UK $\left(5.0 / 10^{5}\right)$ and Japan $\left(4 / 10^{5}\right){ }^{3}$ Researchers have indicated that diabetic peripheral neuropathy (DPN) is a common complication of diabetes and represents a major health problem, including diabetic foot ulceration. ${ }^{4} 5$ Painful diabetic neuropathy (PDN) is one of several clinical syndromes in patients with DPN and presents a major challenge for optimal management. ${ }^{6}$ Some studies have described the symptoms of PDN as a superficial burning pain around the feet and lower extremities and a serious disruption of social functioning and mood. Unlike physiologic pain, neuropathic pain is not self-limiting and not easily 
treated. $^{7}$ However, little is known about the prevalence, patient discomfort and factors associated with PDN in Taiwan, which, in the rural areas, is known to have a high prevalence of type 2 diabetes and foot ulceration. ${ }^{3}$

DPN affects approximately $30-50 \%$ of patients with diabetes. ${ }^{6-8}$ It is estimated that $40-60 \%$ of patients with DPN develop PDN in their lower limbs. ${ }^{9-12}$ Similar to other conditions of neuropathic pain, PDN seems to progress and is often under-reported and difficult to diagnose and treat. ${ }^{1314}$ The net result can be intolerable pain, substantial morbidity and erosion of the quality of life of patients with PDN. ${ }^{15-18}$ It is also important to consider how these patients adapt to, or self-relieve, their painful conditions because some of their behaviours might be associated with, or contribute to, the risk of secondary complications, such as diabetic foot ulcerations, which are a major cause of lower extremity amputations.

Researchers have indicated that PDN primarily involves symmetrical, length-dependent, sensorimotor polyneuropathy attributable to metabolic and microvascular alterations, affects small and/or large sensory fibres and progresses gradually from the distal limbs. ${ }^{19} 20$ Although the efficacy of pharmacological (eg, tricyclic antidepressants, selective serotonin reuptake inhibitors, anticonvulsants and antioxidants such as $\alpha$-lipoic acid) and non-pharmacological (eg, spinal cord stimulation modalities) treatments for PDN appear to be promising, its management still poses a unique challenge owing to the variability in symptoms and responses to treatments. ${ }^{21-23}$ Therefore, identification of modifiable factors of PDN is necessary for the development of early and effective prevention to halt or reverse its progression. In addition, while numerous risk factors for DPN have been identified (ie, hyperglycaemia and cardiovascular and metabolic factors), the associated factors specific to PDN remain largely unexplored. ${ }^{24} 25$

PDN night be a syndrome clinically distinct from DPN. Further investigations of the underlying mechanisms are necessary to determine whether the risk factors related to DPN are also associated with the onset and progression of PDN. Therefore, this study aimed to explore the prevalence, associated factors, discomfort and self-relief behaviours of PDN in Taiwanese rural residents with type 2 diabetes.

\section{METHODS}

\section{Design, sample and setting}

This investigation formed part of a longitudinal cohort study of the effects of health promotion in preventing foot ulceration among rural community residents with type 2 diabetes. A community-based health screening survey was conducted between 2010 and $2013^{26}$ using a cross-sectional descriptive design. The inclusion criteria were as follows: participants must (1) have been diagnosed with type 2 diabetes, reported discomfort, pain or numbness in the lower limbs and be identified by the research team; (2) have the ability to complete the questionnaires in Mandarin or a Taiwanese dialect by face to face interview and (3) agree to participate in the study and provide informed consent before participation. Exclusion criteria were (1) inability to complete the questionnaires and serious learning difficulties and (2) diagnosis of low back pain (eg, lumbar herniated intervertebral disc disease) and various other painful foot problems (eg, gout, osteoarthritis) or experiencing serious complications of diabetes (eg, foot ulceration and minor or major lower limb amputation).

We undertook a two-part approach to study the prevalence and discomfort of PDN. In part 1, the public health nurses in each of the 18 districts carried out a simple random sampling from their local diabetes registration files. According to the total annual quota for free check-ups by the Bureau of Health Promotion, each district was expected to select 40-50 samples for a total of 900 diabetic residents. For example, in the $\mathrm{C}$ district, 200 candidates in the diabetes registration file had a series number and so for this district four cases were selected. In part 2, the discomfort of patients with PDN was explored by a focus group discussion to which all participants were invited.

\section{Measurements}

1. Peripheral neuropathy was assessed with the reliable and valid Michigan neuropathy screening instrument (MNSI), consisting of five parameters: (a) appearance of the feet-inspection of the lower limbs for deformity; (b) foot ulceration; (c) semiquantitative assessment of vibration sensation on the dorsum of the big toe; (d) ankle reflexes and (e) touch-pressure sensation test. Each parameter was graded as $1,0.5$ or 0 with a total score ranging 0 from 10; a MNSI score $>2.0$ was defined as peripheral neuropathy. ${ }^{27} 28$ As an important indicator for the early detection of neuropathy, a semiquantitative assessment of vibration perception threshold was conducted with a $128 \mathrm{~Hz}$ turning fork on the dorsum of the big toe. ${ }^{27-29}$ A $5.07 / 10 \mathrm{~g}$ Semmes-Weinstein monofilament was applied perpendicularly to the test sites of the feet to assess touch-pressure sensation. The inter-rater agreement was $90 \%$ in this study.

2. Peripheral vascular assessment was measured using the ankle brachial index (ABI), which was calculated using ankle/arm pressure with the Cardio-Vision Model (MS-2000). ABI values $\geq 0.9$ and $<0.9$ were classified as normal and peripheral vasculopathy, respectively. ${ }^{27} 30$

3. Glycaemic control and metabolic indicators were measured using fasting blood glucose (FBG), glycohaemoglobin $\left(\mathrm{HbA}_{1} \mathrm{C}\right)$, triglyceride (TG) and total cholesterol (TC) levels, blood pressure and waist circumference (WC). The mean FBG, $\mathrm{HbA}_{1} \mathrm{C}, \mathrm{TC}$ and $\mathrm{TG}$ values during 3 months were retrieved from the household computerised diabetes registries of each district. Blood pressure and WC were measured at the time of the study using standard procedures. WC $(\mathrm{cm})$, a 
measure of central obesity, was determined using the mid-abdominal distance between the last rib margin and the iliac crest. Normal values of these physiological indicators, based on the nationwide standard from the Taiwan Ministry of Health and Welfare, ${ }^{3}$ were as follows: $\mathrm{FBG} \leq 126 \mathrm{mg} / \mathrm{dL}, \mathrm{HbA}_{1} \mathrm{C}<7.0 \%$, TG $\leq 150 \mathrm{mg} / \mathrm{dL}, \quad \mathrm{TC} \leq 200 \mathrm{mg} / \mathrm{dL}, \quad$ systolic/diastolic blood pressure $\leq 130 / 85 \mathrm{~mm} \mathrm{Hg}$ and $\mathrm{WC}<90 \mathrm{~cm}$ and $<80 \mathrm{~cm}$ for men and women, respectively.

4. Basic information and details of health-related behaviours were collected-namely, age, gender, education level, duration of diabetes, body height and weight, history of medication (ie, oral antidiabetes drugs and/or insulin) as prescribed by a physician and health habits (eg, smoking, exercise and wearing of adequate indoor/outdoor shoes). For smoking, participants were classified as 'none or formerly' if they had never smoked or had not smoked for 1 year or 'current users' if they were currently smoking. Participants who never or sometimes exercised were classified as 'not often' and those who usually exercised for a total of $>30 \mathrm{~min} /$ day, three times a week, or $150 \mathrm{~min} /$ week were classified as 'often'.

5. PDN, discomfort and self-relief behaviours were evaluated using the following three structured and semistructured questions: (1) PDN was identified by the research team through a subjective question, "Do you have painful feeling on your feet?" and the answers were classified as "yes" or "no". (2) "Please describe the feelings that you experienced in your leg(s): (a) How do you describe the most discomforting feeling in your leg(s)? (b) Where were the most uncomfortable areas? (c) When did you experience the most discomfort?" and (3) "Please describe how you dealt with or self-relieved the discomfort?". Discomfort and self-relief behaviours were summarised as frequencies and percentages in all PDN participants.

\section{Procedure and ethical considerations}

Upon approval by institutional review boards, participants were recruited by their district public health nurses through regular home visits or by telephone. Participants were informed about the study and received an invitation letter with a brief explanation of the procedures and their opportunity to participate in the study. This study was conducted in collaboration with the Chiayi Bureau of Health Promotion. Potential participants were recruited through the invitation for free annual check-ups by the Department of Health Bureaus. Before the study, informed consent was obtained from each participant by the district public health nurse.

The research team included two physicians specialising in metabolic medicine and wound care, two graduate research assistants with registered nurse certification, 10 community volunteers and 18 public health nurses. To assure competency and reliability in delivering the research protocol, the primary investigator initiated three 6-hour training sessions, allowing all team members to familiarise themselves with the instruments, physiological measures and strategies for focus group interview before the start of the study. After the initial screening of PDN, all participants with evident symptoms or signs of the disease were invited to participate in part 2 of the study-the focus group interviews. All interviews were conducted by eight registered nurses certified as diabetic educators; each focus group discussion held at the local health centre included 6-8 participants and lasted for 30 to $45 \mathrm{~min}$.

\section{Statistical analysis}

Data for demographics, physiological indicators and health-related behaviours were compared using a $\chi^{2}$ test (univariate analysis) between participants with and without PDN. To investigate factors associated with PDN, those variables significant in the univariate analysis $(p<0.05)$ were incorporated into the multivariable logistic regression analysis with forward stepwise selection. ${ }^{31}$ No formal sample size determination and power analysis was carried out in this study because no previous studies had had an effect size calculation. Data analysis was performed using SPSS V.22 (IBM SPSS, Armonk, New York, USA: IBM Corp). All tests were two-sided and $\mathrm{p}<0.05$ was considered to be statistically significant.

\section{RESULTS}

A total of 656 participants were initially enrolled during part 1 of the study; 28 of these left the research procedure owing to difficulty in maintaining contact, not undergoing the physiological measurements, or moving to another residence. Based on the criteria employed, $30.6 \%$ (192/628) participants had PDN and most were women $(63 \%)$. The mean age of participants with PDN was 71 years and half of them had diabetes for $>10$ years (table 1). Approximately, $81.3 \%$ of participants completed elementary school. Participants in the PDN group reported less frequent and irregular exercise $(53.6 \%)$ and abnormal values of MNSI scores (63\%), systolic blood pressure (73\%), central obesity (71\%), $\mathrm{HbA}_{1} \mathrm{C}(63 \%)$ and FBG levels $(61 \%)$.

According to the univariate analysis, participants with PDN were more likely to be women $\left(\chi^{2}=4.52 ; \mathrm{p}=0.034\right)$, have abnormal MNSI $\left(\chi^{2}=7.87 ; \mathrm{p}=0.005\right)$, ABI $\left(\chi^{2}=18.76\right.$; $\mathrm{p}<0.001)$ and TG levels $\left(\chi^{2}=4.79 ; \mathrm{p}=0.029\right)$ and less likely to take part in exercise $\left(\chi^{2}=4.04 ; \mathrm{p}<0.045\right.$; table 1$)$. After adjusting for potential confounders (including gender, age, education, smoking habits), the associated risk factors of PDN were abnormal ABI (OR=3.4; 95\% CI 1.9 to $6.2 ; \mathrm{p}<0.001)$, MNSI $(\mathrm{OR}=1.69 ; 95 \%$ CI 1.0 to 2.6 ; $\mathrm{p}=0.021)$, TG $(\mathrm{OR}=1.61 ; 95 \%$ CI 1.0 to $2.4 ; \mathrm{p}=0.036)$ and being female OR=1.68; 95\% CI 1.1 to $2.4 ; \mathrm{p}=0.022$ ), but not exercise behaviours (table 2).

During part 2 of the study, 192 participants with PDN were invited and all participated in the focus group interviews with agreement forms. A majority of participants used the following descriptions of PDN: "prickling and 
Table 1 Factors associated with painful diabetic neuropathy

\begin{tabular}{|c|c|c|c|c|}
\hline \multirow[b]{2}{*}{ Variables } & \multicolumn{4}{|c|}{ Painful diabetic neuropathy } \\
\hline & $\begin{array}{l}\text { No } \\
\text { n (\%) }\end{array}$ & $\begin{array}{l}\text { Yes } \\
\text { n (\%) }\end{array}$ & $\chi^{2}$ & p Value \\
\hline Gender & & & 4.52 & 0.034 \\
\hline Female & $235(53.9)$ & $121(63.0)$ & & \\
\hline Male & $201(46.1)$ & $71(37.0)$ & & \\
\hline Educational level & & & 1.38 & 0.241 \\
\hline$\leq$ Primary & $336(77.1)$ & $156(81.2)$ & & \\
\hline$\geq$ Secondary & $100(22.9)$ & $36(18.8)$ & & \\
\hline Age (years) & & & 2.42 & 0.299 \\
\hline$<65$ & $122(28.1)$ & $44(22.9)$ & & \\
\hline$\geq 65$ & $312(71.9)$ & $148(77.1)$ & & \\
\hline Duration of diabetes (years) $(n=590)^{*}$ & & & 0.70 & 0.402 \\
\hline$<10$ & 217 (53.2) & $90(49.5)$ & & \\
\hline$>10$ & $191(46.8)$ & $92(50.5)$ & & \\
\hline Smoking habit & & & 0.42 & 0.515 \\
\hline Never or formerly & 322 (73.9) & $137(71.4)$ & & \\
\hline Current users & $114(26.1)$ & $55(28.6)$ & & \\
\hline Exercise & & & 4.04 & 0.045 \\
\hline Often (ie, regular) & $240(55.0)$ & $89(46.4)$ & & \\
\hline Not often (ie, irregular) & $196(45.0)$ & $103(53.6)$ & & \\
\hline MNSI $(n=612)^{\star}$ & & & 7.87 & 0.005 \\
\hline$\leq 2$ & $208(48.8)$ & $68(36.6)$ & & \\
\hline$>2$ & 218 (51.2) & $118(63.4)$ & & \\
\hline ABI $(n=616)^{*}$ & & & 18.76 & $<0.001$ \\
\hline$\geq 0.9$ & $387(90.6)$ & $147(77.8)$ & & \\
\hline$<0.9$ & $40(9.4)$ & $42(22.2)$ & & \\
\hline Systolic blood pressure $(n=623)^{\star}$ & & & & \\
\hline$\leq 130 \mathrm{~mm} \mathrm{Hg}$ & $141(32.6)$ & $51(26.7)$ & 2.19 & 0.139 \\
\hline$>130 \mathrm{~mm} \mathrm{Hg}$ & $291(67.4)$ & 140 (73.3) & & \\
\hline Diastolic blood pressure $(n=623)^{*}$ & & & 2.41 & 0.121 \\
\hline$\leq 85 \mathrm{~mm} \mathrm{Hg}$ & $339(78.5)$ & $139(72.8)$ & & \\
\hline$>85 \mathrm{~mm} \mathrm{Hg}$ & $93(21.5)$ & $52(27.2)$ & & \\
\hline Waist circumference $(\mathrm{cm}) \dagger(\mathrm{n}=614)^{*}$ & & & 0.28 & 0.869 \\
\hline Normal & $113(26.5)$ & $53(28.3)$ & & \\
\hline Abnormal & 314 (73.5) & $134(71.7)$ & & \\
\hline $\mathrm{HbA}_{1} \mathrm{C}(\%)(\mathrm{n}=457)^{*}$ & & & 0.13 & 0.721 \\
\hline$\leq 7.0$ & $125(38.8)$ & $50(37.0)$ & & \\
\hline$>7.0$ & 197 (61.2) & $85(63.0)$ & & \\
\hline Fasting blood glucose $(n=499)^{\star}$ & & & 0.56 & 0.454 \\
\hline$\leq 126 \mathrm{mg} / \mathrm{dL}$ & $121(35.4)$ & $61(38.9)$ & & \\
\hline$>126$ mg/dL & $221(64.6)$ & $96(61.1)$ & & \\
\hline Total cholesterol $(n=411)^{\star}$ & & & 0.25 & 0.618 \\
\hline$\leq 200 \mathrm{mg} / \mathrm{dL}$ & $183(64.7)$ & $86(67.2)$ & & \\
\hline$>200 \mathrm{mg} / \mathrm{dL}$ & $100(35.3)$ & $42(32.8)$ & & \\
\hline Triglyceride $(n=437)^{\star}$ & & & 4.79 & 0.029 \\
\hline$\leq 150 \mathrm{mg} / \mathrm{dL}$ & $192(63.4)$ & $70(52.2)$ & & \\
\hline$>150 \mathrm{mg} / \mathrm{dL}$ & $111(36.6)$ & $64(47.8)$ & & \\
\hline
\end{tabular}

stinging pain", "dry and painful", "burning pain", "inexplicable dullness and excruciating pain" and "my legs do not belong to me" (table 3). Examples of participants' responses included "Actually, I don't know how to describe the uncomfortable and annoying feelings...it is just like a needle stinging or a knife stabbing your legs. The shooting pain is just below the legs". The major discomfort areas perceived by the participants were "base and/or dorsum of the feet or toes" and the time of discomfort was reported to be "at night and during sleeping", "anytime or all day long" and "during walking".

The most frequently reported self-relief behaviours were "keep moving", "don't know what to do", "trying domestic non-prescription products" and "seeking help" 
Table 2 Logistic regression of factors associated with painful diabetic neuropathy

\begin{tabular}{|c|c|c|c|c|c|}
\hline Variables & B & SE & OR & p Value & $95 \% \mathrm{Cl}$ \\
\hline \multicolumn{6}{|c|}{ Ankle brachial pressure index } \\
\hline $\begin{array}{l}<0.9 \\
\geq 0.9^{\star}\end{array}$ & 1.244 & 0.304 & 3.40 & $<0.001$ & 1.9 to 6.2 \\
\hline \multicolumn{6}{|c|}{ Michigan neuropathy screening index } \\
\hline $\begin{array}{l}>2 \\
\leq 2^{*}\end{array}$ & 0.524 & 0.226 & 1.69 & 0.021 & 1.0 to 2.6 \\
\hline \multicolumn{6}{|l|}{ Gender } \\
\hline $\begin{array}{l}\text { Female } \\
\text { Male }^{*}\end{array}$ & 0.521 & 0.228 & 1.68 & 0.022 & 1.1 to 2.4 \\
\hline \multicolumn{6}{|c|}{ Triglyceride (mg/dL) } \\
\hline $\begin{array}{l}>150 \\
\leq 150^{\star}\end{array}$ & 0.476 & 0.226 & 1.61 & 0.036 & 1.0 to 2.4 \\
\hline Exercise & & & & & \\
\hline $\begin{array}{l}\text { Irregular } \\
\text { Regular* }\end{array}$ & 0.375 & 0.223 & 1.45 & 0.093 & 0.9 to 2.3 \\
\hline
\end{tabular}

(table 4). Self-relief behaviours included "I just keep walking" or "I keep moving or rotating my toes", "I do exercise on my feet", "I massage my feet or sometimes try to kick, knead, tap, or stride out with my feet", "I really don't know which hospital or which department I can visit to help with my discomfort", "Can you tell me what I should do?", "I just forget about it; mostly I tried to ignore it", "Sometimes, I wipe spirits or rub tiger balm (a sort of local herbal liquid or cream for headache relief in Taiwan)", "I paste adult creams and a herbal patch...sometimes it provides relief for a short period of time", "I visit the physician, but it was far away from my house", "Doctor gave me pain medications" and "I asked for Chinese medicine and the doctor here gave me acupuncture".

\begin{tabular}{lc}
$\begin{array}{l}\text { Table } 3 \text { Reported discomfort with painful diabetic } \\
\text { neuropathy ( } \mathrm{n}=192)\end{array}$ & $\mathbf{n}(\%)$ \\
\hline Feelings of most discomfort & $61(31.8)$ \\
\hline $\begin{array}{l}\text { Prickling, stabbing, tingling, numbness, } \\
\text { stinging }\end{array}$ & $52(27.1)$ \\
Dry and painful & $37(19.3)$ \\
Burning pain & $28(14.6)$ \\
Inexplicable dullness...excruciating & $14(7.3)$ \\
My legs do not belong to me... & \\
\hline Areas of most discomfort & $173(90.1)$ \\
\hline One or both bases or dorsal areas or toes of & \\
the feet & $19(9.9)$ \\
\hline Lower extremities...below knee & $76(39.6)$ \\
\hline Most discomfort felt & $73(38.0)$ \\
\hline During sleeping and worse at night & $27(14.1)$ \\
Anytime or all day long & $12(6.3)$ \\
During walking & $4(2.1)$ \\
\hline When waking up in the morning & \\
During cold days &
\end{tabular}

\section{DISCUSSION}

According to the literature, only a few researchers have explored the prevalence of PDN, its associated factors, patient discomfort and self-relief behaviours among residents with diabetes in rural Taiwan. Furthermore, nurse-led health promotion programmes for preventing foot ulceration through a multidisciplinary approach are limited. The nurse-led health promotion programme in this study included collaboration with the Bureau of Health, public health nurses in 18 districts of Chiayi County and physicians in the local hospital and faculties in the nursing school. Although random sampling was not performed, analysis of a large rural sample yielded findings that were sufficiently reliable to assist the development of a nursing intervention in primary healthcare for early detection of PDN and prevention of foot ulceration. Two important findings related to the association between PDN and associated factors. (1) Several factors were modifiable, including abnormal values of ankle brachial pressure, Michigan neuropathy and TG levels. (2) Little attention to, or treatment of, patient discomfort was provided by primary healthcare workers, despite its high prevalence.

The prevalence of PDN in this study (31\%) seems to be higher than that reported in other countries $(14 \%$ in Belgium, ${ }^{17} 10-20 \%$ in the USA, ${ }^{15}{ }^{32}$ and $16.2 \%$ in the UK). ${ }^{33}$ This disparity might be due to variations in the measurements used, duration of diabetes and the sample size. We hypothesised that the raised prevalence of PDN in this study population might have been due to the increased elderly population and prevalence of diabetes in Taiwan. Participants with PDN in this study were more likely to be women, have abnormal MNSI scores, ABI, TG levels and less likely to take part in exercise. After controlling for potential confounders, these four predictors for PDN (ie, ABI, MNSI scores, gender and TG levels) were similar to those previously reported. ${ }^{34-36}$ For instance, $71 \%$ of participants with central obesity and hypertriglyceridaemia in our study had PDN, which was consistent with the study by Smith and Singleton, ${ }^{24}$ in which three or more abnormal risk factors, obesity and hypertriglyceridaemia significantly increased the risk for DPN. In addition, Smith and Singleton ${ }^{24}$ also found that obesity and hypertriglyceridaemia were related to the loss of small unmyelinated axons, whereas glycaemic control (ie, $\mathrm{HbA}_{1} \mathrm{C}$ ) was related to the loss of large myelinated fibre.

The TG levels, gender, and the early signs of preclinical DPN measured with ABI (peripheral vasculopathy) and MNSI scores (peripheral neuropathy) were found to be significant factors for PDN in this study. However, it was difficult to compare our findings with those of other studies because investigations into associated risk factors for PDN are limited. According to our understanding of the pathophysiology, PDN is primarily attributable to metabolic and microvascular alterations and affects small or large sensory fibres, leading to direct abnormalities in the somatosensory system. As a result, any change in 
Table 4 Most common self-relief behaviours in painful diabetic neuropathy $(n=192)$

\begin{tabular}{l}
\hline Self-relief behaviours \\
\hline Keep moving \\
I always keep walking... keep moving or rotating my toes... do exercise... massage... kicking...kneading, tapping, \\
treading on the feet \\
Don't know what to do \\
Can you tell me... what should I do? \\
I don't know which hospital can treat my problems \\
Seeking help, but feel no use \\
Can you help me with my problems? \\
Trying domestic non-prescription or complementary products. \\
Sometimes I wipe spirits, rub tiger balm, paste adult creams, paste herbal patch, smear pang tiger balm, smear \\
peppermint oil strip... \\
Seeking help \\
Visit a physician at local health centre \\
Take analgesic medication from pharmacy store or local medical centre .... \\
Use acupuncture from Chinese medicine \\
Others \\
Using hot water \\
Wearing socks to keep warm
\end{tabular}

peripheral vasculopathy $^{30}$ or peripheral neuropathy is postulated to be theoretically associated with the development of PDN.

According to the responses obtained from this study, most participants with PDN received little attention or treatment for their discomfort from healthcare providers. These results were similar to other studies in which only $38.6 \%$ of French patients ${ }^{37}$ and $28 \%$ of patients in Belgium $^{17}$ received appropriate treatment for their neuropathic pain. More importantly, participants in our study even reported that they engaged in potentially harmful self-relief behaviours for PDN. These risky harmful behaviours included receiving acupuncture, using hot water and kicking their own weakened legs in an effort to reduce the discomfort. These behaviours might result in fatal complications, such as diabetic foot ulceration. Such behaviours need to be considered given that diabetes is the most common cause of death in the southwestern coastal region, Chiayi County, Taiwan. ${ }^{3}$

As in other studies, ${ }^{38-40}$ PDN was characterised as feelings of prickling, stabbing, tingling, numbness, stinging, burning pain and inexplicable dullness and excruciating pain around the base or dorsal areas of the feet, which were present throughout the day, at night or when sleeping. Although we did not explore the quality of life in those affected by PDN in greater detail, about one-third of participants with PDN had discomfort during their illness. Researchers have indicated that PDN can lead to sleep disturbance, anxiety, depression and significantly affects the overall health-related quality of life. ${ }^{39} 40$ Therefore, it is important for primary healthcare providers to establish a referral system, especially for patients with PDN in remote areas and provide them with appropriate pharmacological or non-pharmacological treatments designed to achieve a certain degree of pain relief.

\section{Limitations}

Although a large sample of participants was recruited and we employed some valid and reliable measures, nevertheless, the following study limitations should be considered: (1) missing data might have led to insignificant results for $\mathrm{FBG}, \mathrm{HbA}_{1} \mathrm{C}$ and $\mathrm{TG}$, primarily retrieved from computer records at the district health centre, as risk factors for PDN; (2) participants recruited from only one county might limit the generalisability of study findings; (3) self-reports of personal health-related behaviours (eg, frequency of exercise and cigarette smoking) might be under-reported owing to recall bias associated with ageing or comorbidity of some chronic diseases. In addition, this study does not classify former smokers into the user group; this result might reduce the effects of smoking on PDN and (4) PDN was identified through a subjective question, although the selection criteria excluded various feet problems. These results might have produced misclassification of subjects with PDN. Given the limitations of this study, future studies should involve a data monitoring protocol during the study period and a more complete dataset, especially for glycaemic control or metabolic features.

\section{CONCLUSION}

Despite some limitations, we demonstrated associations among abnormal ABI, MNSI, TG levels and PDN in rural areas. Moreover, a relatively high prevalence of PDN was found in this study. PDN was characterised by feelings of discomfort such as prickling, stinging or burning pain, inexplicable dullness and excruciating pain in the lower limbs. Moreover, the participants in this study were older, had PDN, lived in rural areas and did not receive adequate attention or appropriate treatment from healthcare providers. To enable the early 
identification of high-risk groups with PDN, especially in an elderly population, future research needs to include routine screenings of MNSI, ABI, glycaemic control, metabolic indicators and pain assessments during the annual check-up programmes. Additionally, the development and evaluation of self-relief behaviours to halt or reverse the progression of PDN need to be initiated and evaluated.

\section{Author affiliations}

${ }^{1}$ Department of Nursing, Chang Gung University of Science and Technology, Taoyun, Taiwan

${ }^{2}$ Division of Cardiology, Chang Gung Memorial Hospital, Yunlin, Taiwan

${ }^{3}$ Division of Internal Medicine, Chang Gung Memorial Hospital, Yunlin, Taiwan

${ }^{4}$ Psychosocial \& Community Health and Health Services, Schools of Nursing and Public Health, University of Washington, Seattle, Washington, USA

${ }^{5}$ Department of Nursing, Chang Gung University of Science and Technology, Chiayi, Taiwan

${ }^{6}$ Department of Nursing, Chang Gung University, Taoyuan, Taiwan

${ }^{7}$ Professor Research Fellow, Chang Gung Memorial Hospital, Chiayi, Taiwan

Acknowledgements We thank all participants in this study and staff at the Chiayi Bureau of Health Promotion for their support, which made this study possible.

Contributors S-WJ and M-YC: setting up and designing the study, data analysis, development of the discussion section and editing of the final draft for publication. W-NC and M-SL: setting up the study and data collection. RDB: development of the discussion section and editing of the final draft. All authors read and approved the final manuscript.

Funding The study was supported by a grant from the National Science Council (NSC 101-2314-B-255-003) and Chang Gung Memorial Hospital (BMRP 148)

Competing interests None declared.

Patient consent Obtained

Ethics approval This study was approved by the institutional review board of the ethical committee of Chang Gung Memorial Hospital (IRB 100-4628B).

Provenance and peer review Not commissioned; externally peer reviewed.

Data sharing statement No additional data are available.

Open Access This is an Open Access article distributed in accordance with the Creative Commons Attribution Non Commercial (CC BY-NC 4.0) license, which permits others to distribute, remix, adapt, build upon this work noncommercially, and license their derivative works on different terms, provided the original work is properly cited and the use is non-commercial. See: http:// creativecommons.org/licenses/by-nc/4.0/

\section{REFERENCES}

1. Danaei G, Finucane MM, Lu Y, et al. National, regional and global trends in fasting plasma glucose and diabetes prevalence since 1980: systematic analysis of health examination surveys and epidemiological studies with 370 country-years and 2.7 million participants. Lancet 2011;378:31-40.

2. Shaw JE, Sicree RA, Zimmet PZ, et al. Global estimates of the prevalence of diabetes for 2010 and 2030. Diabetes Res Clin Pract 2010;87:4-14.

3. Health Promotion Administration (HPA), Ministry of Health and Welfare. Diabetes. http://www.hpa.gov.tw/BHPNet/Web/HealthTopic/ Topic.aspx?id=200712250014 (accessed 28 May 2015).

4. Khalil $\mathrm{H}$. Painful diabetic neuropathy management. Int $J$ Evid Based Healthc 2013;11:77-9.

5. Singleton JR, Smith AG. The diabetic neuropathies: practical and rational therapy. Semin Neurol 2012;32:196-203.

6. Veves A, Backonja M, Malik RA. Painful diabetic neuropathy: epidemiology, natural history, early diagnosis and treatment options. Pain Med 2008;9:660-74.
7. Marchettini $P$, Teloni L, Formaglio $F$, et al. Pain in diabetic neuropathy case study: whole patient management. Eur J Neuro 2004;1:12-21.

8. American Diabetes Association. Standards of medical care in diabetes-2011. Diabetes Care 2011:34:S11-61.

9. Gordois A, Scuffham P, Shearer A, et al. The health care costs of diabetic peripheral neuropathy in the US. Diabetes Care 2003;26:1790-5.

10. Morales-Vidal S, Morgan C, McCoyd M. Diabetic peripheral neuropathy and the management of diabetic peripheral neuropathic pain. Postgrad Med 2012;124:145-53.

11. Tentolouris N, Alexiadou K, Makrilakis K. Standard and emerging treatment options for diabetic neuropathy. Curr Pharm Des 2014;20:3689-704.

12. Abbott CA, Malik RA, van Ross ER. Prevalence and characteristics of painful diabetic neuropathy in a large community-based diabetic population in the U.K. Diabetes Care 2011;34:2220-4.

13. Callaghan BC, Cheng HT, Stables CL. Diabetic neuropathy: clinical manifestations and current treatments. Lancet Neurol 2012;11:521-34.

14. Spallone V. Management of painful diabetic neuropathy: guideline guidance or jungle? Curr Diab Rep 2012;12:403-13.

15. Tesfaye S, Vileikyte L, Rayman G. Painful diabetic peripheral neuropathy: consensus recommendations on diagnosis, assessment and management. Diabetes Metab Res Rev 2011;27:629-38.

16. Arnstein P. Chronic neuropathic pain: issues in patient education Pain Manag Nurs 2004;5:34-41.

17. Kaur $S$, Pandhi $P$, Dutta $P$, et al. Painful diabetic neuropathy: an update. Ann Neurosci 2011;18:168-75.

18. Van Acker K, Bouhassira D, De Bacquer D. Prevalence and impact on quality of life of peripheral neuropathy with or without neuropathic pain in type 1 and type 2 diabetic patients attending hospital outpatients clinics. Diabetes Metab 2009;35:206-13.

19. Baron R, Binder A, Wasner G. Neuropathic pain: diagnosis, pathophysiological mechanisms and treatment. Lancet Neurol 2010;9:807-19.

20. Forbes JM, Cooper ME. Mechanisms of diabetic complications. Physiol Rev 2013;93:137-88.

21. Griebeler ML, Morey-Vargas OL, Brito JP, et al. Pharmacologic interventions for painful diabetic neuropathy: an umbrella systematic review and comparative effectiveness network meta-analysis. Ann Intern Med 2014:161:639-49.

22. Sultan A, Gaskell H, Derry S, et al. Duloxetine for painful diabetic neuropathy and fibromyalgia pain: systematic review of randomised trials. BMC Neurol 2008;8:29.

23. de Vos CC, Meier K, Zaalberg PB, et al. Spinal cord stimulation in patients with painful diabetic neuropathy: a multicentre randomized clinical trial. Pain 2014;155:2426-31.

24. Smith AG, Singleton JR. Obesity and hyperlipidemia are risk factors for early diabetic neuropathy. J Diabetes Complicat 2013;27:436-42.

25. Tesfaye S, Boulton AJ, Dyck PJ. Diabetic neuropathies: update on definitions, diagnostic criteria, estimation of severity and treatments. Diabetes Care 2010;33:2285-93.

26. Chen MY, Huang WC, Peng YS, et al. Effectiveness of a health promotion programme for farmers and fishermen with type-2 diabetes in Taiwan. J Adv Nurs 2011;67:2060-7.

27. Chang $\mathrm{CH}$, Peng YS, Chang CC. Useful screening tools for preventing foot problems of diabetics in rural areas: a cross-sectional study. BMC Public Health 2013;13:612.

28. Moghtaderi A, Bakhshipour A, Rashidi H. Validation of Michigan neuropathy screening instrument for diabetic peripheral neuropathy. Clin Neurol Neurosurg 2006;108:477-81.

29. Feng Y, Schlösser FJ, Sumpio BE. The Semmes Weinstein monofilament examination as a screening tool for diabetic peripheral neuropathy. J Vasc Surg 2009;50:675-82.

30. Alzamora MT, Forés R, Baena-Díez JM. The Peripheral Arterial disease study (PERART/ARTPER): prevalence and risk factors in the general population. BMC Public Health 2010;10:38-48.

31. Polit DF, Hungler BP. Multivariate data analysis, in Nursing Research. 6th edn. Philadelphia: Lippincott, 1999:490-3.

32. Argoff CE, Cole BE, Fishbain DA. Diabetic peripheral neuropathic pain: clinical and quality-of-life issues. Mayo Clin Proc 2006;81: S3-11.

33. Daousi C, MacFarlane IA, Woodward A. Chronic painful peripheral neuropathy in an urban community: a controlled comparison of people with and without diabetes. Diabetes Care 2004;21:976-82.

34. Callaghan BC, Feldman E, Liu J. Triglycerides and amputation risk in patients with diabetes: ten-year follow-up in the DISTANCE study. Diabetes Care 2011;34:635-40. 
35. Tesfaye S, Chaturvedi N, Eaton SE. Vascular risk factors and diabetic neuropathy. N Engl J Med 2005;352:341-50.

36. Wiggin TD, Sullivan KA, Pop-Busui R, et al. Elevated triglycerides correlate with progression of diabetic neuropathy. Diabetes 2009;58:1634-40.

37. Bouhassira D, Letanoux M, Hartemann A. Chronic pain with neuropathic characteristics in diabetic patients: a French cross-sectional study. PLOS ONE 2013;8:e74195.
38. Boulton AJ, Malik RA, Arezzo JC. Diabetic somatic neuropathies. Diabetes Care 2004;27:1458-86.

39. Zelman DC, Brandenburg NA, Gore M. Sleep impairment in patients with painful diabetic peripheral neuropathy. Clin J Pain 2006;22:681-5

40. Nordanstig J, Wann-Hansson C, Karlsson J. Vascular quality of life questionnaire- 6 facilitates health-related quality of life assessment in peripheral arterial disease. J Vasc Surg 2014;59:700-7. 